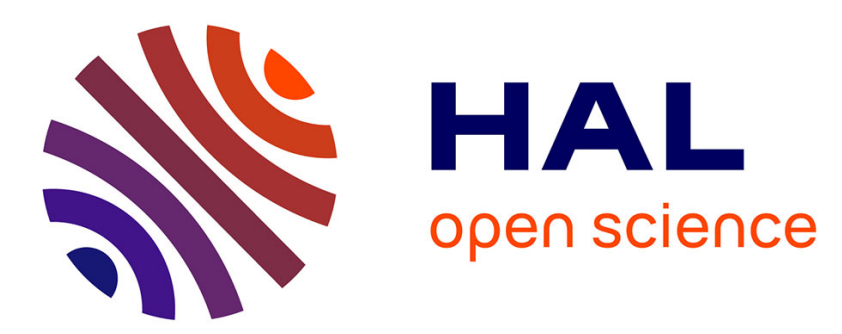

\title{
Neutron diffraction of calcium aluminosilicate glasses and melts
}

Louis Hennet, James W.E. Drewitt, Daniel R. Neuville, Viviana Cristiglio, Jad Kozaily, Séverine Brassamin, Didier Zanghi, Henry E. Fischer

\section{- To cite this version:}

Louis Hennet, James W.E. Drewitt, Daniel R. Neuville, Viviana Cristiglio, Jad Kozaily, et al.. Neutron diffraction of calcium aluminosilicate glasses and melts. Journal of Non-Crystalline Solids, 2016, 451, pp.89 - 93. 10.1016/j.jnoncrysol.2016.05.018 . hal-01395538

\section{HAL Id: hal-01395538 \\ https://hal.science/hal-01395538}

Submitted on 31 Mar 2021

HAL is a multi-disciplinary open access archive for the deposit and dissemination of scientific research documents, whether they are published or not. The documents may come from teaching and research institutions in France or abroad, or from public or private research centers.
L'archive ouverte pluridisciplinaire HAL, est destinée au dépôt et à la diffusion de documents scientifiques de niveau recherche, publiés ou non, émanant des établissements d'enseignement et de recherche français ou étrangers, des laboratoires publics ou privés. 
Hennet, L., Drewitt, J. W. E., Neuville, D. R., Cristiglio, V., Kozaily, J., Brassamin, S., Zanghi, D., \& Fischer, H. E. (2016). Neutron diffraction of calcium aluminosilicate glasses and melts. Journal of NonCrystalline Solids, 451, 89-93.

https://doi.org/10.1016/j.jnoncrysol.2016.05.018

Peer reviewed version

License (if available):

CC BY-NC-ND

Link to published version (if available):

10.1016/j.jnoncrysol.2016.05.018

Link to publication record in Explore Bristol Research

PDF-document

This is the author accepted manuscript (AAM). The final published version (version of record) is available online via Elsevier at 10.1016/j.jnoncrysol.2016.05.018.

\section{University of Bristol - Explore Bristol Research}

General rights

This document is made available in accordance with publisher policies. Please cite only the published version using the reference above. Full terms of use are available:

http://www.bristol.ac.uk/red/research-policy/pure/user-guides/ebr-terms/ 


\title{
Neutron diffraction of calcium aluminosilicate glasses and melts.
}

\author{
Louis Hennet $^{\mathrm{a}, 1}$, James W.E. Drewitt ${ }^{\mathrm{b}}$, Daniel R. Neuville ${ }^{\mathrm{c}}$, Viviana Cristiglio ${ }^{\mathrm{d}}$, Jad Kozaily ${ }^{\mathrm{e}}$, \\ Séverine Brassamin ${ }^{\mathrm{a}}$, Didier Zanghi ${ }^{\mathrm{a}}$, Henry E. Fischer ${ }^{\mathrm{d}}$, \\ ${ }^{a}$ CNRS-CEMHTI, University of Orleans, 1d avenue de la Recherche Scientifique, 45071 Orléans cedex 2, \\ France \\ ${ }^{\mathrm{b}}$ School of Earth Sciences, University of Bristol, Wills Memorial Building, Queens Road, \\ Bristol, BS8 1RJ, UK \\ 'IPGP-CNRS, Géomatériaux, Sorbonne Paris Cite, 75005 Paris, France \\ ${ }^{\mathrm{d}}$ Institut Laue Langevin (ILL), 6 rue Jules Horowitz, BP 156, 38042 Grenoble, France \\ ${ }^{\mathrm{e}}$ Rafik Hariri University, P.O. Box 10, Damour-Chouf 2010, Lebanon
}

\begin{abstract}
The combination of neutron diffraction with aerodynamic levitation and laser heating, pioneered by Neville Greaves and co-workers about 15 years ago, is an important tool for studying the structure of liquid melts. Since the first work on liquid $\mathrm{Al}_{2} \mathrm{O}_{3}$ published in 2001, the technique has been largely improved and experiments are now routinely performed at neutron sources, providing interesting structural information on various materials.

In this paper, the structure of glass-forming compounds in the system $\mathrm{CaO}-\mathrm{Al}_{2} \mathrm{O}_{3}-\mathrm{SiO}_{2}$ was measured by applying neutron diffraction with aerodynamic levitation. Results obtained in the liquid state above the melting point and from the glass at room temperatures are presented. Various compositions were studied by increasing the silica content and by changing the ratio $\mathrm{CaO} / \mathrm{Al}_{2} \mathrm{O}_{3}$. As observed using other methods, the main structural changes relate to modification of the Al-O short range order.
\end{abstract}

\footnotetext{
${ }^{1}$ Corresponding author: Louis.hennet@cnrs-orleans.fr
} 


\section{Introduction}

Calcium aluminosilicate, $\mathrm{CaO}-\mathrm{Al}_{2} \mathrm{O}_{3}-\mathrm{SiO}_{2}$ (CAS), glasses and melts are of both technological and scientific interest. In particular their good optical and mechanical properties $[1,2]$ and their refractory nature make them attractive for a wide range of industrial applications, including the production of concrete $[3,4]$. CAS melts are also the main components of slags produced in furnaces in coal and steel industries. In geosciences, they are of fundamental importance as they form a significant fraction of the composition of geological magmas [5,6,7].

The thermodynamic and dynamic properties of CAS show a strong dependence with the microscopic structure [8]. It is, therefore, important to study in detail the high temperature properties of the melts. In order to study the liquid state, we used the aerodynamic levitation technique combined with $\mathrm{CO}_{2}$ laser heating. This technique was pioneered about 15 years ago by Neville Greaves with teams from the University of Aberystwyth (UK) and the CNRSCEMHTI in Orléans (France) $[9,10]$.

In this paper, we present results obtained from various CAS glass compositions at both room temperature and in the liquid state. Some of these glass compositions have already been studied by x-ray diffraction at room temperature $[11,12]$ but only a few have been analyzed by neutron diffraction, in particular along the join $\mathrm{R}=1.57[11,13]$. Here and in the following, the $\mathrm{R}$ value is defined as the ratio $\mathrm{CaO} / \mathrm{Al}_{2} \mathrm{O}_{3}$. In the liquid state only the compositions without silica have been studied extensively $[14,15]$. Our first results obtained for CAS liquids with low silica content have been reported recently in combination with Molecular Dynamics (MD) simulations. [16]. A recent work is also devoted to the study of CAS slags with other compositions [17]. The objective of the present investigation is to complete these previous works by extending the range of CAS compositions studied by neutron diffraction in 
order to better understand the structure of the glasses and melts, in relation with the observed properties.

\section{Technical details}

\subsection{Sample preparation}

The samples were prepared from high purity crystalline $\mathrm{CaCO}_{3}, \mathrm{Al}_{2} \mathrm{O}_{3}$ and $\mathrm{SiO}_{2}$ powders. The appropriate quantities of powders were melted at $1600^{\circ} \mathrm{C}$ for 4 hours in a platinum crucible and then quenched to room temperature. The resulting materials were grinded and re-melted several times in order to ensure a good homogeneity of the glasses. A full description of the sample preparation is described in Neuville et al. [18]. The required quantity of material for each sample was then levitated in air using an argon-oxygen $(\sim 3 \%)$ gas flow and melted by laser heating. Rapid quenching, achieved by switching off the laser power, resulted in the formation, on cooling, of solid spherical samples with diameters of $4 \mathrm{~mm}$ (for the glass measurements) and $2.7 \mathrm{~mm}$ (to investigate the liquid state under levitation). The samples studied are listed in Table I. As in previous works, we employ the notation Cax.y, where $x$ and $y$ refer to the molar concentration of $\mathrm{SiO}_{2}$ and $\mathrm{Al}_{2} \mathrm{O}_{3}$, respectively, and $1-x-y$ is the $\mathrm{CaO}$ molar content. The precise molar compositions of the glasses are reported in Neuville et al [7,19].

\subsection{Neutron diffraction}

The neutron diffraction (ND) measurements were made using the aerodynamic levitation and laser heating device installed on the D4C diffractometer [20] at the Institut Laue-Langevin (Grenoble, France), as described in ref [21]. Diffraction measurements were taken for the liquid samples at temperatures above the melting point for all studied compositions, for the empty levitation device inside the diffraction chamber, and for vanadium samples with the aim of making an absolute normalization of the scattering intensity to barns.st ${ }^{-1}$.atom ${ }^{-1}$. The neutron wavelength and zero-angle shift were determined by 
fitting the positions of the Bragg peaks obtained from a reference nickel sample. The neutron wavelength used during the experiment was $0.4969 \AA$, giving a scattering vector Q-range of 0.3-23.6 $\AA^{-1}$. The data processing was performed using the program CORRECT [22] which corrects the data for attenuation, background, multiple scattering and inelasticity (Placzek) effects. Since, for various technical reasons, there can be appreciable uncertainties with respect to the relative beam-illuminated volumes of the vanadium samples compared to the CAS samples using the levitation technique, we found it more accurate and reliable to perform an auto-normalization of the scattered intensity from the CAS samples. Specifically, the high- $Q$ asymptote of the sample's intensity (after accounting for the Placzek inelasticity effect) was scaled so as to be equal to the theoretical self-scattering that depends only on the known composition of the sample. We then also confirmed that the atomic number density required for accurate normalization of the $r$-space function $G(r)$ (see equation in section 3.2) was equal to the theoretical atomic number density, thereby acting as an $r$-space consistency check of our auto-normalization performed in $Q$-space.

\section{Experimental results}

\subsection{Structure factors}

The total structure factors $S(Q)$ of all studied samples at room temperature and in the liquid state are presented in figure 1. For all compositions, room and high temperature measurements are very similar with only a few differences due principally to thermal effects which increase the structural disorder. This means that the short range order is very close in the glasses and melts. As observed for the compositions along the composition lines $\mathrm{R}=1$ and 3, by increasing the $\mathrm{SiO}_{2}$ content, the first peak (FSDP) in $S(Q)$ shifts towards lower $Q$ values with a higher intensity. This shows that the degree of intermediate-range order, higher in the glassy state, is improved by incorporating silica into the structure. Although the FSDPs 
are less visible in the liquid state, they seem to be at the same positions found for the glasses and the same $Q$ shift is observed with increasing $\mathrm{SiO}_{2}$ content.
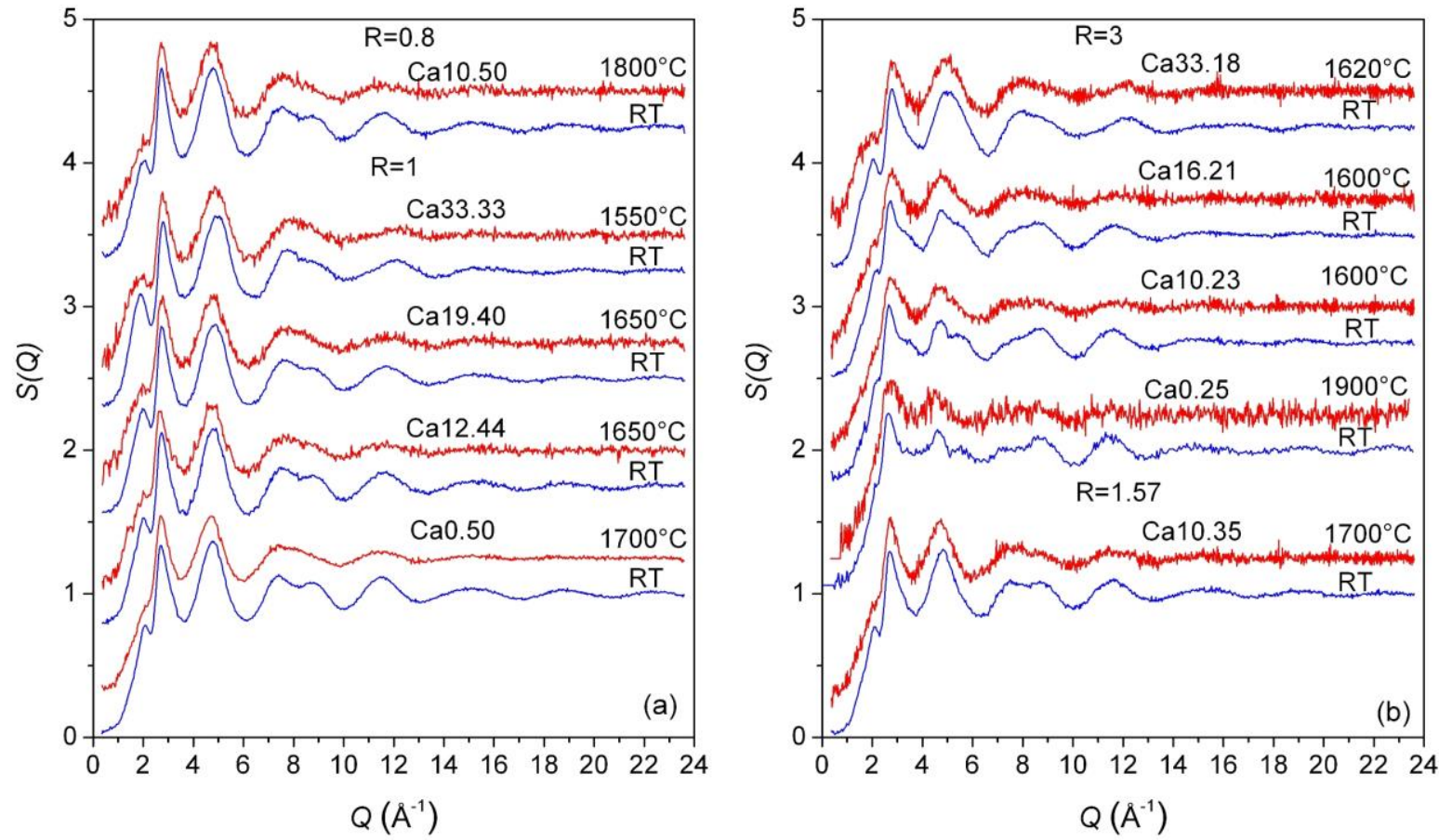

Figure 1. Total structure factors $S(Q)$ of the CAS glasses and liquids for $\mathrm{R}=0.8$ and 1 (a) and $\mathrm{R}=1.57$ and 3 (b). The liquid temperatures are reported in the figure.

\subsection{Pair distribution functions}

The total pair distribution function is calculated from the structure factor by the Fourier transform:

$$
G(r)-1=\frac{1}{2 \pi^{2} r \rho_{0}} \int_{0}^{\infty}[S(Q)-1] Q \sin (Q r) \mathrm{d} Q,
$$

where $\rho_{0}$ denotes the atomic number density. All values are listed in Table 1 . For glasses they were calculated using densities measured with the Archimedean method applying toluene as immersion liquid [7,23]. For melts, they were derived from densities determined by Courtial and Dingwell [24].. 

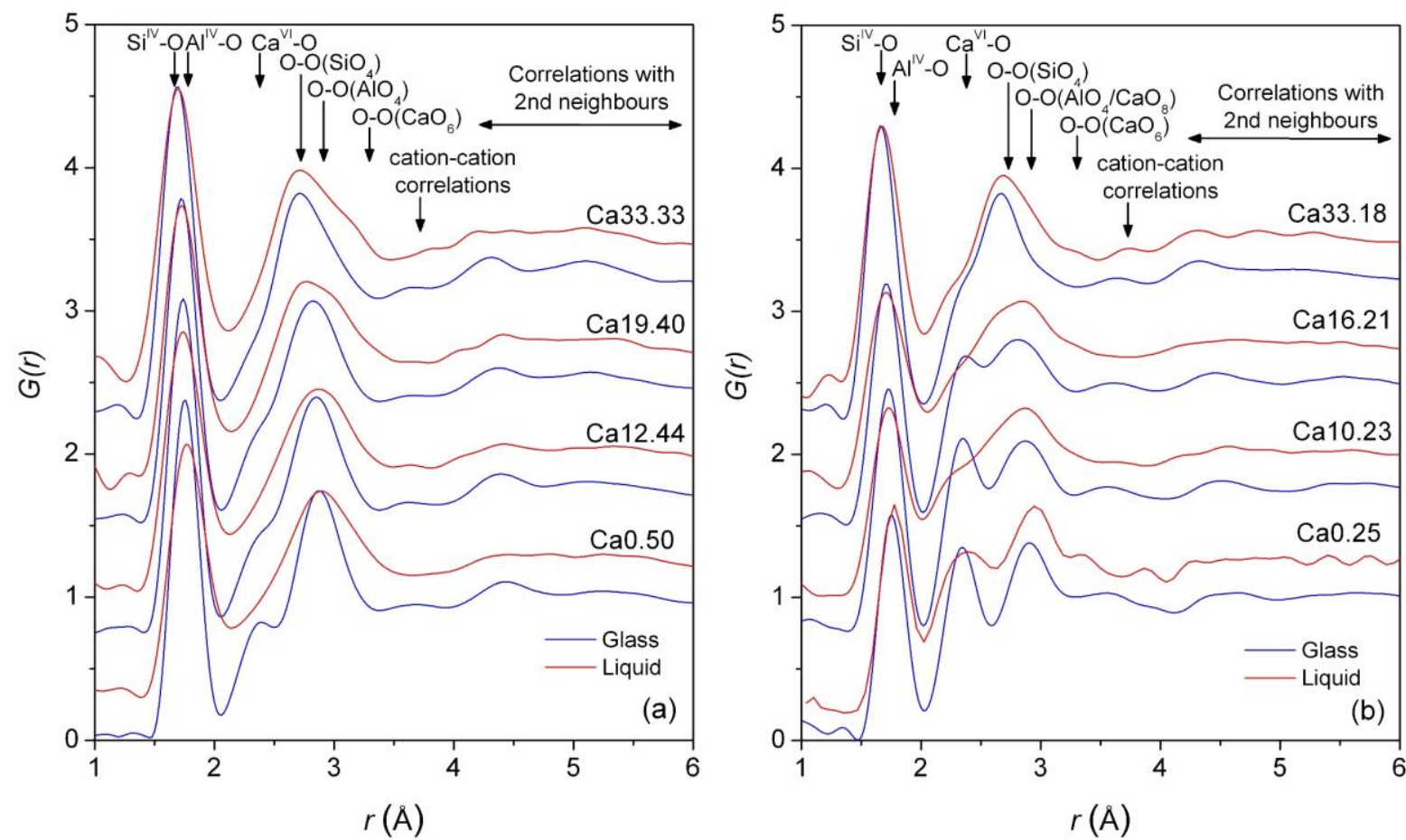

Figure 2. Total pair distribution functions $G(r)$ for the CAS glasses and liquids along the composition lines $\mathrm{R}=1$ (a) and $\mathrm{R}=3$ (b). The positions of the various $\mathrm{O}-\mathrm{O}$ correlations, as calculated assuming $\mathrm{SiO}_{4}$ and $\mathrm{AlO}_{4}$ tetrahedra and $\mathrm{CaO}_{6}$ octahedra, are shown as a guide. The oscillations above $r=4 \AA$ arise from correlations between second neighbours.

Figure 2 shows the total pair distribution functions $G(r)$ for all the compositions studied along the joins 1 and 3.

The calcium aluminate compositions $\mathrm{Ca} 0.50$ and $\mathrm{Ca} 0.25$ have previously been studied in detail using neutron and $\mathrm{x}$-ray scattering techniques in combination with MD and RMC simulations $[14,25]$. For these two compositions, the first peak found respectively at 1.76 and $1.74 \AA$ in the glass arises purely from the contribution of the nearest neighbour $\mathrm{Al}-\mathrm{O}$ correlations. On melting, the observed shift of its position towards higher values is characteristic of an increase of the proportion of $\mathrm{AlO}_{5}$ units in the structure (see data reported in Table I). In all G(r)s, the peak at around 2.3-2.35 $\AA$ arises from Ca-O bonds and is less resolved in the melt. In particular, the $\mathrm{Ca}-\mathrm{O}$ peak broadens in the $\mathrm{Ca} 0.25$ composition and becomes barely resolvable from the next $\mathrm{O}-\mathrm{O}$ correlations in the $\mathrm{Ca} 0.50$ melt, thus complicating the structural analysis. Further measurements of the $\mathrm{Ca} 0.50$ glass and melt have been made by applying the method of neutron diffraction with isotopic substitution (NDIS) 
[26], which combined with the use of MD simulations, provides much more detailed structural information on the $\mathrm{Ca}-\mathrm{O}$ coordination environment.

With the introduction of silica, the first peak corresponds to an overlapped contribution from both the Al-O and the Si-O nearest neighbour pairs. Its position moves gradually toward the $\mathrm{Si}-\mathrm{O}$ bond distance as the $\mathrm{SiO}_{2}$ content is increased. It becomes more difficult to determine the respective contributions of the $\mathrm{Si}-\mathrm{O}$ and $\mathrm{Al}-\mathrm{O}$ bonds, and the $\mathrm{Ca}-\mathrm{O}$ correlations are also affected by the associated increase of the O-O contribution from $\mathrm{SiO}_{4}$ tetrahedra that largely overlaps the peak and make the analysis more difficult. For composition along the join $\mathrm{R}=1.57$, a detailed structural study have been made using $\mathrm{x}$-ray and neutron diffraction experiment [13] and with Reverse Monte Carlo and MD simulations [27].

NMR experiments performed on all these glass compositions show that $\mathrm{Al}$ is 4-fold coordinated along the join $\mathrm{R}=3$ up to $20 \%$ silica content and with small amounts of AlO5 units above and along the join $\mathrm{R}=1$ (values are reported in table I for all compositions) [19]. For all liquids, only a small enlargement is observed on the high $r$ side of the first peak. This is in accordance with an increase of the number of the $\mathrm{AlO}_{5}$ units observed to elongate the Al$\mathrm{O}$ distance in the $\mathrm{Ca} 0.50$ melt [26]. With CAS compounds, cation-cation correlations contribute much less to the total $G(r)$ than cation-O bonds and give rise only to small features found around $3.5 \AA$.

The determination of the coordination numbers and bond distances is performed using a Gaussian fit to the correlation function $T(r)=4 \pi r \rho_{0} g(r)$ as described in Hannon and Parker [28]. Results of the fits are presented in figure 3 for glasses (a) and melts (b). In each case, only the two extreme compositions along the lines $\mathrm{R}=1$ and 3 are presented. The complete results are summarized in table I.

For the silicate samples, the Gaussian fit was performed by fixing the coordination number of the $\mathrm{Si}-\mathrm{O}$ bond around 4 leading to a $\mathrm{Si}-\mathrm{O}$ bond length of $1.62 \AA$ in the glasses and 
$1.65 \AA$ in the liquid state. For all samples, the average coordination numbers of $\mathrm{Al}-\mathrm{O}$ bonds are found to be around 4 in accordance with NMR results [19]. Assuming perfect tetrahedra (angle of 109.47), it is possible to estimate the O-O bond length for $\mathrm{SiO}_{4}$ and $\mathrm{AlO}_{4}$ as 2.62 and $2.83 \AA$, respectively, in the glass. The $\mathrm{Ca}-\mathrm{O}$ distance found around $2.32 \AA$ is characteristic of 6 -fold coordinated $\mathrm{Ca}$ as found in previous works $[13,14,16,30]$. Considering perfect $\mathrm{CaO} 6$ octahedra, an O-O distance of $3.28 \AA$ is calculated $(2.32 \times \sqrt{ } 2)$. The positions of these three calculated $\mathrm{O}-\mathrm{O}$ bond distances are indicated in figure 2. This shows that the shape of the wide O-O correlations which give distances between 2.5 and $3.5 \AA$ can be reasonably described by the contribution of these 3 pairs. However, higher coordinated $\mathrm{Ca}$ found in previous works [13,29] would give rise to O-O correlations at positions between those for $\mathrm{AlO}_{4}$ and $\mathrm{CaO}_{6}$ polyhedra and cannot be excluded. Indeed, the $\mathrm{Ca}-\mathrm{O}$ correlations for 7- and 8fold coordinated $\mathrm{Ca}$ are expected around 2.4 and $2.5 \AA$ and if present they are thus difficult to resolve.

As seen previously, accurate information about the Ca-O local structure is difficult to obtain due to large overlapping contributions from the O-O correlations and temperature effects which broaden the peaks. This precludes the determination of $\mathrm{Ca}-\mathrm{O}$ coordination number from our total structure measurements. By comparison to XANES experiments at the Ca-Kedge, $\mathrm{Ca}$ was estimated to be in regular 6-fold coordination in $\mathrm{C} 3 \mathrm{~A}$ glass $(\mathrm{Ca} 0.25)$, 7fold coordination in CA (Ca50.00) with localized 6- to 7-fold coordination sites in CAS glasses $[18,30]$. A recent NDIS study of the Ca50.00 composition found a Ca coordination number of 6.2 in the liquid state and around 6.4 in the glass [26]. This shows that the use of more selective techniques than conventional ND are important in order to more precisely determine the atomic arrangement around Ca atoms. Recently, NDIS experiments have been made to investigate the structure of liquid $\mathrm{Ca} 0.25$ [31]. 

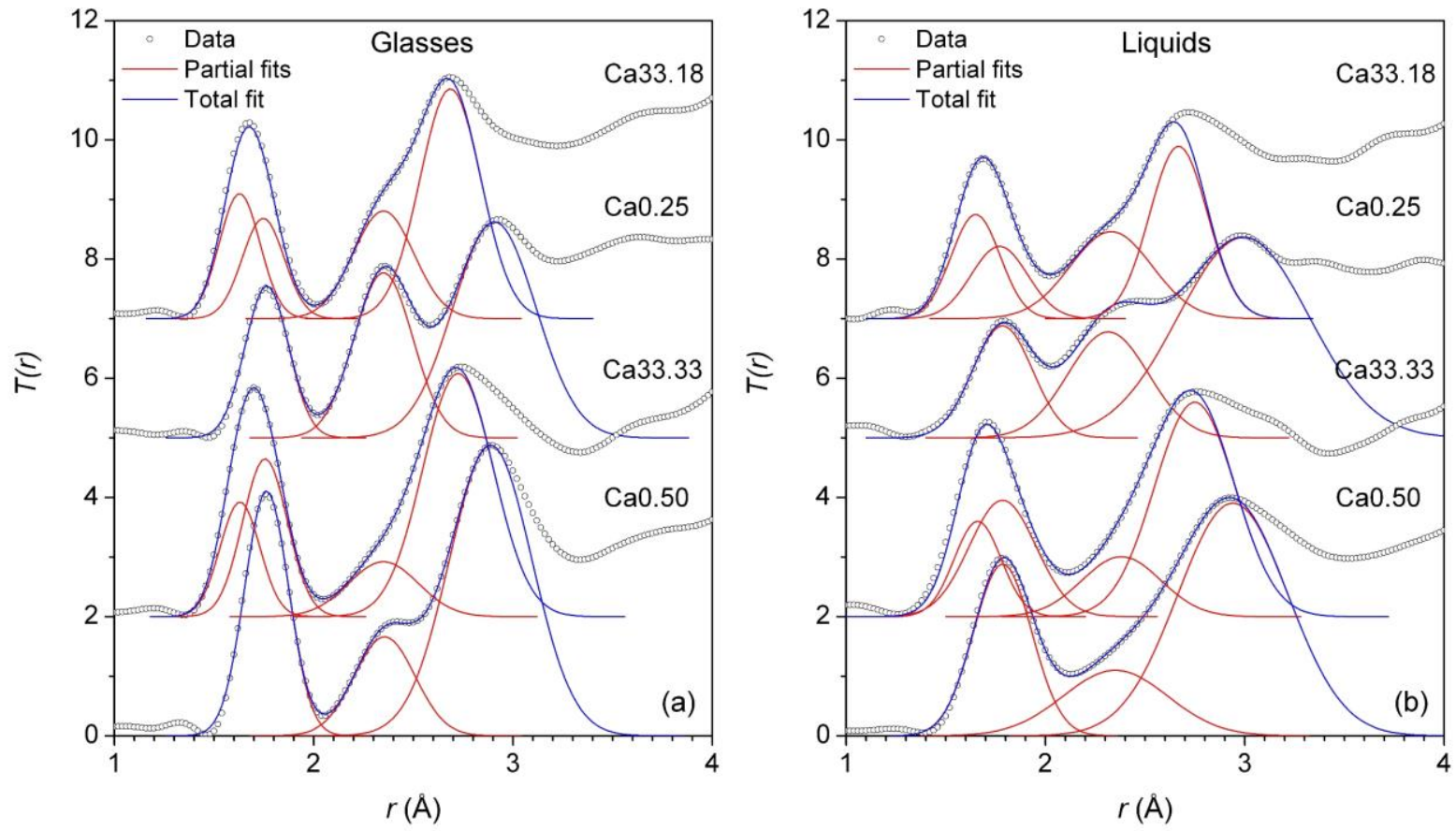

Figure 3. Total correlation function $T(\mathrm{r})$ for the compositions bearing 0 or $33 \%$ of $\mathrm{SiO}_{2}$ along the joins $\mathrm{R}=1$ and 3 for glasses (a) and melts (b). The partial fits and the final result are compared with the experimental data.

\section{Discussion}

As shown in various papers $[26,29,30]$, the $\mathrm{Ca} 0.25$ glass $(\mathrm{R}=3)$ has a structure composed by tetrahedraly coordinated $\mathrm{Al}, \mathrm{Q}^{2}$ species with 2 bridging (BO) and 2 nonbridging (NBO) oxygen atoms, and $\mathrm{Ca}$ in a regular six fold coordination. With increasing the $\mathrm{Al}_{2} \mathrm{O}_{3}$ content, $\mathrm{Al}$ changes from $\mathrm{Q}^{2}$ to a mixture of $\mathrm{Q}^{3}$ and $\mathrm{Q}^{4}$ species for $\mathrm{Ca} 0.39(\mathrm{R}=1.57)$ [27] and $\mathrm{Q}^{4}$ in the $\mathrm{Ca} 0.50$ glass $(\mathrm{R}=1)$ associated to some proportion of $\mathrm{AlO5}$ units to ensure the cationic mobility as shown in $[19,30]$. This change in the Q species distribution implies a decrease of the number of NBO leading to the observed increase of the viscosity with the $\mathrm{Al}_{2} \mathrm{O}_{3}$ content [30].

With adding silica along the join $\mathrm{R}=3$, the distribution of $\mathrm{Al}$ into $\mathrm{Q}$ species increases also from $\mathrm{Q}^{2}$ to $\mathrm{Q}^{4}$ for the Ca23.21 (not studied in this paper) as shown in Al NMR, Raman spectroscopy and XANES at the Al K-edge [19]. In this case, the increase of the $\mathrm{SiO}_{2}$ content, produces an increase of the polymerization of $\mathrm{Al}$ from $\mathrm{Q}^{2}$ to $\mathrm{Q}^{4}$ because $\mathrm{Si}$ atoms are in $\mathrm{Q}^{0}$ 
species and concentrate all NBOs around them. For the Ca33.18 composition, the Q species of $\mathrm{Si}$ increase from $\mathrm{Q}^{0}$ to $\mathrm{Q}^{1}$ whereas $\mathrm{Al} \mathrm{Q}$ species stay in $\mathrm{Q}^{4}$ and some $\mathrm{AlO5}$ units appears.

Along the join $R=1$, which is the charge compensation line, the glasses are then fully polymerised and by using XANES experiments at the Ca absorption edge, Neuville et al explained the evolution of the FSDP by an increase of the ring size from 4 to 5 members for low and high silica content [18]. When $\mathrm{R}$ is increased, Ca atoms play the role of network modifiers with the creation of NBOs leading to less ordered structure.

In the silicate glasses, the first peak in $G(r)$ is a weighted sum of the $\mathrm{Si}-\mathrm{O}$ and $\mathrm{Al}-\mathrm{O}$ correlations. By fixing the tetrahedral configuration of the $\mathrm{SiO}_{4}$ units during the fit to $T(r)$, it is possible to derive reasonable Al-O bond lengths of $1.74-1.76 \AA$ and $1.76-1.78 \AA$ in the glasses and melts, respectively. The Al-O coordination numbers are slightly higher in the melts, reflecting an increased proportion of $\mathrm{AlO}_{5}$ units for most of the compositions. It can be noted that with an error bar of \pm 0.5 neutron scattering technique is not sensitive enough to reproduce the evolution of the coordination numbers determined with NMR at room temperature (see table I). For $\mathrm{Ca} 0.25$, if the distance $\mathrm{Al}-\mathrm{O}$ at room temperature found at 1.74 $\AA$ is characteristic of purely 4-fold coordinated $\mathrm{Al}$ in accordance with the amount of AlO5 (Table1), the found coordination number of 4.2 is a bit high, although it is within the error bar of \pm 0.5 . This could be explained with a possible small influence of the $\mathrm{Ca}-\mathrm{O}$ correlation (highest concentration) but more probably by an overestimation of the density, measured on a sample using a different cooling rate. New density measurements will be performed directly on the measured sample and ongoing $\mathrm{x}$-ray scattering experiment on theses glass compositions will also enable to conclude. At high temperatures, there is no precise determination of the $\mathrm{AlO5}$ content and the main results come from MD simulation (some of them are reported in Table I). For C3A, one can see that different values can be obtained, depending on the calculation method. 
The study of $\mathrm{Ca}-\mathrm{O}$ correlations is more difficult due to large overlapping $\mathrm{O}-\mathrm{O}$ contributions. From a simple Gaussian fit, it seems that the bond distances (summarized in Table I) and thus the coordination number, doesn't change by increasing the silica content along the joins $\mathrm{R}=1$ and 3. Depending on the temperature and the composition, the $\mathrm{Ca}-\mathrm{O}$ coordination number is then expected to be between 6 and 7 by comparison with a previous study [26,30]. However, a more sophisticated fit including all contributions is needed to get more accurate information on the $\mathrm{Ca}-\mathrm{O}$ correlation and take into account existing $\mathrm{Ca}$ with higher coordination.

The small effect of the increase of the silica content was also observed by Cormier et al along the join $R=1.57[13,27]$. They found that even at low silica contents, silicon becomes part of the aluminate network and thus attributed the changes observed on the dynamics to structural rearrangements at medium range order.

The large number of atomic pairs in the CAS system complicates the data analysis. In order to have a full description of the short range order for these compositions, additional high temperature EXAFS measurements at the $\mathrm{Ca}-\mathrm{K}$ absorption edge would be useful. Indeed, existing works are limited to very few melt compositions [30]. Using diffraction, it is necessary to use more selective techniques. The $\mathrm{Ca}$ X-ray absorption edge at $4.038 \mathrm{keV}$ precludes the use of anomalous scattering experiments as performed with liquid $\mathrm{Y}_{2} \mathrm{O}_{3}$ [32]. NDIS is then a good solution, despite the long counting times required due to the relatively small size of the levitated spheres.

In addition of these experimental techniques, interesting information can be also derived from MD and/or RMC simulations. Drewitt et al studied various calcium aluminate melts including $\mathrm{Ca} 0.50$ and $\mathrm{Ca} 0.25$ [14]. From these simulations, they derived information about the distribution of coordination numbers for $\mathrm{Ca}$ and $\mathrm{Al}$ and the various bond angle distributions provide insight into the connectivity of polyhedra. L. Cormier et al studied in details some glasses along the join $\mathrm{R}=1.57$ [27] and in addition of the previous 
informationthey got also information on the ring statistics, the distribution of the $\mathrm{Q}$ species, the number of NBOs, or the existence of triclusters. This interplay between triclusters, NbOs and AlO5 units was also studied by MD simulation for the low silica content composition along the join $\mathrm{R}=1$ [16] enabling to derive also valuable information on the dynamics [33].

\section{Conclusion}

This study shows that the use of neutron diffraction combined with levitation techniques is an important tool for deriving structural information from liquid materials and to obtain useful information about coordination numbers and bond lengths.

In this work we showed that limited structural changes are observed by increasing the ratio $\mathrm{CaO} / \mathrm{Al}_{2} \mathrm{O}_{3}$ or the $\mathrm{SiO}_{2}$ content in CAS glasses. At high temperatures a small increase in the Al-O coordination number is observed. This is due to the presence of a larger fraction of $\mathrm{AlO}_{5}$ units. The short range order around $\mathrm{Ca}$ remains almost unchanged over the whole composition range studied. These observations are in good agreement with previous results obtained with other techniques. The combination of these results with simulations will make it possible to derive reliable information in the liquid state and in particular about the dynamics.

\section{Acknowledgements}

We thank Alain Bertoni for help with the diffraction experiments and the Institut LaueLangevin for the beamtime allocation. We also thank the French National Research Agency for its financial support under the grant No. ANR-13-BS08-0012-01. 


\begin{tabular}{|c|c|c|c|c|c|c|c|c|c|}
\hline & $\mathrm{R}$ & $\mathrm{T}\left({ }^{\circ} \mathrm{C}\right)$ & $\rho_{0}\left(\AA^{-3}\right)$ & $\begin{array}{c}r^{\mathrm{Si-O}} \\
\pm 0.02 \AA \\
\end{array}$ & $\begin{array}{c}r^{\mathrm{Al}-\mathrm{O}} \\
\pm 0.02 \AA \\
\end{array}$ & $\begin{array}{c}r^{\mathrm{Ca}-\mathrm{O}} \\
\pm 0.05 \AA \\
\end{array}$ & $\begin{array}{c}\mathrm{CN}^{\mathrm{Si}-\mathrm{O}} \\
\pm 0.5 \\
\end{array}$ & $\begin{array}{c}\mathrm{CN}^{\mathrm{Al}-\mathrm{O}} \\
\pm 0.5\end{array}$ & AlO5 units \\
\hline \multirow{2}{*}{ Ca10.50 } & \multirow{2}{*}{0.8} & RT & 0.0783 & 1.62 & 1.75 & 2.32 & 4.04 & 4.09 & $4.2 \%$ \\
\hline & & 1800 & 0.0745 & 1.65 & 1.76 & 2.34 & 4.05 & 4.26 & I \\
\hline \multirow{2}{*}{$\mathrm{Ca} 0.50$} & \multirow{2}{*}{1} & RT & 0.0773 & l & 1.75 & 2.35 & l & 4.05 & $3.5 \%$ \\
\hline & & 1700 & 0.0734 & 1 & 1.78 & 2.32 & 1 & 4.20 & $15 \%, 18 \%[14,25]$ \\
\hline \multirow{2}{*}{ Ca12.44 } & \multirow{2}{*}{1} & RT & 0.0772 & 1.62 & 1.76 & 2.34 & 4.02 & 4.07 & $4.5 \%$ \\
\hline & & 1650 & 0.0737 & 1.65 & 1.77 & 2.32 & 4.05 & 4.18 & $10 \%[33]$ \\
\hline \multirow{2}{*}{ Ca19.40 } & \multirow{2}{*}{1} & RT & 0.0773 & 1.62 & 1.76 & 2.34 & 4.08 & 4.05 & $5.8 \%$ \\
\hline & & 1650 & 0.0737 & 1.65 & 1.77 & 2.34 & 4.05 & 4.10 & $8 \%[33]$ \\
\hline \multirow{2}{*}{ Ca33.33 } & \multirow{2}{*}{1} & RT & 0.0770 & 1.62 & 1.75 & 2.34 & 4.05 & 4.06 & $8 \%$ \\
\hline & & 1550 & 0.0735 & 1.65 & 1.77 & 2.36 & 4.05 & 4.23 & 1 \\
\hline \multirow{2}{*}{ Ca10.35 } & \multirow{2}{*}{1.57} & RT & 0.0758 & 1.62 & 1.76 & 2.35 & 4.04 & 4.11 & $2.6 \%$ \\
\hline & & 1700 & 0.0716 & 1.65 & 1.77 & 2.32 & 4.05 & 4.15 & 1.2 [27] \\
\hline \multirow{2}{*}{$\mathrm{Ca} 0.25$} & \multirow{2}{*}{3} & RT & 0.0723 & l & 1.74 & 2.34 & l & 4.20 & $0 \%$ \\
\hline & & 1900 & 0.0632 & I & 1.77 & 2.32 & 1 & 4.20 & $5 \% ; 10 \%[14,34]$ \\
\hline \multirow{2}{*}{ Ca10.23 } & \multirow{2}{*}{3} & RT & 0.0736 & 1.62 & 1.75 & 2.34 & 4.02 & 4.05 & $0 \%$ \\
\hline & & 1600 & 0.0684 & 1.65 & 1.77 & 2.30 & 4.05 & 4.18 & I \\
\hline \multirow{2}{*}{ Ca16.21 } & \multirow{2}{*}{3} & RT & 0.0744 & 1.62 & 1.75 & 2.34 & 4.08 & 4.09 & $0 \%$ \\
\hline & & 1600 & 0.0691 & 1.65 & 1.76 & 2.30 & 4.04 & 4.20 & 1 \\
\hline \multirow{2}{*}{ Ca33.18 } & \multirow{2}{*}{3} & RT & 0.0759 & 1.62 & 1.74 & 2.34 & 4.05 & 4.12 & $7 \%$ \\
\hline & & 1620 & 0.0703 & 1.65 & 1.76 & 2.32 & 4.05 & 4.19 & / \\
\hline
\end{tabular}

Table I Summary of the structural parameters for all samples. The join composition is indicated as well as the proportion of AlO5 units in glasses determined by NMR [19] and melts from MD simulations. 


\section{References}

1 M. E. Lines, J. B. MacChesney, K. B. Lyons, A. J. Bruce, A. E. Miller, and K. Nassau, J. Non-Cryst. Solids 107 (1989) 251-260

2 F. T. Wallenberger and S. D. Brown, Compos. Sci. Technol. 51 (1994) 243-263

3 F. Puertas, A. Fernandez-Jimenez, Cement Concrete Comp. 25 (2003) 287-292

4 C. Li, H. Sun, L. Li, Cement Concrete Res. 40 (2010) 1341-1349

5 S. Jahn, P. Madden, Phys. Earth Planet. In. 162 (2007) 129-139

6 N. De Koker, Geochim. Cosmochim. Acta. 74 (2010) 5657 -5671

7 D. R. Neuville, L. Cormier and D. Massiot, Geochim. Cosmochim. Acta, 68 (2004) 50715079

8 B. O. Mysen, Structure and Properties of Silicate Melts, Elsevier, Amsterdam, 1988

9 C. Landron, L. Hennet, J. P. Coutures, T. Jenkins, C. Aletru, N. Greaves, A. K. Soper, and G. Derbyshire, Rev. Sci. Instrum. 71 (2000) 1745-1751

10 C. Landron, L. Hennet, T. Jenkins, N. Greaves, J. P. Coutures, A. K. Soper, Phys. Rev. Lett. 86 (2001) 4839-4842

11 L. Cormier, D. R. Neuville, G. Calas, J. Am. Ceram. Soc. 88 (2005) 2292-2299

12 V. Petkov, S. J. L. Billinge, S. D. Shastri, and B. Himmel, Phys. Rev. Let. 86 (2000) 34363439

13 L. Cormier, D.R. Neuville, G. Calas, J. Non-Cryst Solids 274 (2000) 110-114

14 J. W. E. Drewitt, S. Jahn, V. Cristiglio, A. Bytchkov, M. Leydier, S. Brassamin, H. E. Fischer, L. Hennet, J. Phys. Cond. Mat. 23 (2011) 155101

15 L. Hennet, I. Pozdnyakova, A. Bytchkov, D. L. Price, G. N. Greaves, M. Wilding, S. Fearn, C. M. Martin, D. Thiaudière, J.-F. Bérar, N. Boudet, M.-L. Saboungi, J. Chem. Phys. 126 (2007) 074906 
16 N. Jakse, M. Bouhadja, J. Kozaily, J. W. E. Drewitt, L. Hennet, D. R. Neuville, H. E. Fischer, V. Cristiglio, A. Pasturel, Appl. Phys. Lett. 101 (2012) 201903

17 M. Liu, A.Jacob, C. Schmetterer, P.J. Masset, L. Hennet, H.E. Fischer, J. Kozaily, S.Jahn, A. Gray-Weale, J. Phys. Cond. Mat., 28 (2016) 135102.

18 D. R. Neuville, L. Cormier, A. M. Flank, V. Briois and D. Massiot, Chem. Geol. 213 (2004) 153-163

19 D. R. Neuville, L. Cormier, D. Massiot, Chem. Geol. 229 (2006) 173-185

20 H. E. Fischer, G. J. Cuello, P. Palleau, D. Feltin, A. C. Barnes, Y. S. Badyal, J. M. Simonson, Appl. Phys. A 74 (2002) S160-S162

21 L. Hennet, I. Pozdnyakova, A. Bytchkov, V. Cristiglio, P. Palleau, H. E. Fischer, G. J. Cuello, M. R. Johnson, P. Melin, D. Zanghi , S. Brassamin , J.-F. Brun, D. L. Price, M.-L. Saboungi, Rev. Sci. Instrum. 77 (2006) 053903

22 M.A. Howe, R. L. McGreevy, P. Zetterström P, NFL Studsvik Internal Report CORRECT: a correction programme for neutron diffraction data (1996)

23 D.R. Neuville, Private communication.

24 P. Courtial and D. B. Dingwell, Geochim. Cosmochim. Acta 59 (1995) 3685-3695

25 V. Cristiglio, L. Hennet, G. J. Cuello, I. Pozdnyakova, M. Leydier, J. Kozaily, H. E.

Fischer, M. R. Johnson, D. L. Price, J. Non-Cryst. Solids 356 (2010) 2492-2496

26 J. W. E. Drewitt, L. Hennet, A. Zeidler, S. Jahn, P. S. Salmon, D. R Neuville, H. E. Fischer, Phys. Rev. Lett. 109 (2012) 235501

27 L; Cormier,D. Ghaleb, D.R. Neuville, J.M. Delaye, G. Calas, J. Non-Crystal. Solids. 332, (2003) 255-270.

28 A.C. Hannon, J.M. Parker, J. Non-Cryst. Solids 274 (2000) 102-109

29 D.R.Neuville, G.S. Henderson, L. Cormier, D. Massiot, Am. Min. 95 (2010) 1580-1589 
30 D.R. Neuville, L. Cormier, A.M. Flank, D. de Ligny, J. Roux, P Lagarde, Am. Min. 93 (2008) 228-234

31 J. W. E. Drewitt, A. C. Barnes, S. Jahn, S. C. Kohn, M. J. Walter, A. Novikov, D. R.

Neuville, H. E. Fischer, L. Hennet In Prep. (2016)

32 L. Hennet, D. Thiaudière, C. Landron, P. Melin, D. L. Price, J.-P. Coutures, J.-F. Bérar,

M.-L. Saboungi, Appl. Phys. Lett. 83 (2003) 3305-3307

33 M. Bouhadja, N. Jakse, and A. Pasturel, J. Chem. Phys. 138 (2013) 224510

34 V. Cristiglio, PhD thesis, University of Orleans (2008) 